\title{
Evaluation of Tourism E-Commerce User Satisfaction
}

\author{
Guanghai Tang, Yangtze Normal University, Chongqing, China \& Shaanxi Normal University, Xi‘an, China
}

Hui Zeng, Yangtze Normal University, Chongqing, China

\begin{abstract}
According to the UNWTO, within 4 to 5 years, the proportion of tourism e-commerce in e-commerce will reach $20 \%-25 \%$. The purpose of this paper is to improve the inadequacy of tourism e-commerce in customer experience, to conduct customer e-commerce satisfaction surveys, and to draw customers' dissatisfaction with tourism e-commerce. The experimental results show that the overall customer satisfaction is 2.6128. According to the division of the scale vector, the overall satisfaction of the travel e-commerce customers is generally level. The first-level fuzzy comprehensive evaluation is 0.0967 , $0.1696,0.3366,0.2469,0.502$. According to the principle of maximum membership degree, the evaluation grades of R3 and R5 in the first-level fuzzy comprehensive evaluation are "unsatisfactory," that is, the tourism-supporting services and contract-performance services become the main factors affecting customer satisfaction. In order to improve customer satisfaction, the tourism e-commerce platform should strengthen the management of tourism-supporting services and contract-fulfillment services.
\end{abstract}

\section{KEYWORDS}

Discrete Dimorphic Fuzzy Set, Satisfaction Survey, Tourism Assessment, Tourism E-Commerce

\section{INTRODUCTION}

With the development of social economy and the improvement of people's economic level, people's demands for life are getting higher and higher. The Internet has gradually integrated into the tourism industry (Pereira et al., 2016; Zhang et al., n.d.). The traditional travel agency has a long time, the ground floor storefront, and the residents feel safe. The price is at the bottom, but there are too many available and unnecessary things to buy, which are not cheap together. However, shopping is too much and shopping time is also large. Time is too fast, not to travel but to go wild. Tourism e-commerce: There are less tourism business websites, and the overall development level of tourism e-commerce is low (Pileliene et al., 2016; Choi et al., 2019). However, with the development of the Internet era, traditional tourism will gradually integrate into tourism E-commerce (Hopp et al., 2015).

Until today, many travel agencies have not noticed most travel agencies, including famous ones. At present, most consumers choose different travel modes according to traditional service methods, and ignore the application of e-commerce itself (Hamidi et al., 2017). However, from a cost perspective, to build an e-commerce website, it costs a lot of money to purchase related hardware and software equipment, but it is difficult to guarantee revenue. From an implementation point of view, e-commerce 
is new, and many new companies have no clear method of implementing e-commerce. In addition to insufficient information on travel websites, many travel agencies only introduced the introduction to rides and sightseeing knowledge, etc., and did not make full use of e-commerce to set up "straight bridges" between merchants (WAIL, 2018). It cannot provide a comprehensive, professional, and practical series of travel services, and cannot give full play to the infinite charm of online travel. The function of the travel website is very simple, the website performance is simple, the content is not updated in time, the search function is poor, and the virtual community does not play an appropriate role and cannot answer. Travel companies also lack talent. At present, the hardware and software required for the establishment of travel website information are relatively mature (Getele et al., 2018; Yang et al., n.d.). Building a travel website, management and application requires extensive knowledge and high skills. Entrepreneurs must have advanced network technology and e-commerce knowledge, as well as marketing management knowledge. The proficiency in e-commerce and the academic ability to be familiar with travel is insufficient. Tourism enterprises cannot develop e-commerce smoothly because of lack of talent (Ting et al., 2016). People have credit security and important network security. Lack of confidence in online security may affect the resistance of online transactions. Illegal intrusion poses a threat to e-commerce. Due to concerns about network security, many users have a negative attitude towards online payment, and as a result, data such as credit cards have been stolen by network hackers. Moreover, online transactions require a series of user authentication procedures. The privacy of many users is disclosed on the Internet, and ordinary people who are increasingly worried about privacy are reluctant to conduct online transactions (Yin, 2018). At present, online payment has not yet been resolved, and the payment model of "online transaction and online payment" is still widely used. Despite the rapid development of e-commerce, the penetration rate must be increased. According to a survey, the current netizens who shop online in China are still limited to young people. Most middle-aged people with economic strength have not yet developed. Except that some people do not use computers, the bigger reason is that people have e-commerce cash registers (Suel et al., 2017). worry. If the tour company's description of the amusement facility is inconsistent, the tour team will consist of exaggerated publicity and inferior native products. Ensuring online travel company promotion is the real method, and ensuring the travel agency's own evaluation method has become a problem for the further development of the travel network market (Ravi et al., 2019; He et al., 2016; Xiao et al., 2019).

Scale survey andLikert scale method: As a company, individuals cannot think that they have established a complaint and recommendation system to understand the satisfaction and dissatisfaction of internal customers fully. Practice shows that not all unsatisfied internal customers will complain. Therefore, companies cannot simply use internal complaints to measure internal customer satisfaction (Tsai 2018). Authors should also conduct further investigations through questionnaires or test scales to obtain direct internal customer satisfaction (Neidhardt et al., 2017). In these internal customer satisfaction tests, grid rulers are appropriate and effective options for questionnaire surveys and measurements. The millimeter-scale structure is relatively simple to operate, and widely used (Shen, 2017). Based on the original overall scale in 1932, it was developed by the American social psychologist Likat. The ratio is composed of a series of sentences, and each sentence has 5 answers: "strongly agree", "agree", "not necessarily required", "disagree", and "strongly disagree". The total score of each respondent's attitude is the total score of answers to each question. This total score can show his attitude or different status in this ratio. The basic step in constructing the grid-scale is to collect most (50 to 100) reports related to the measurement concept. According to the measurement concept, each measurement item is divided into two categories: "preferred" and "not ideal". There are many good or unfavourable items in general measurement items. The internal client is selected to test all items in advance. The internal client must display the strengths or weaknesses of each item and execute them in the following instructions. When choosing, the so-called " 5 -point system" ratio is usually used. The items from very dissatisfied to very dissatisfied were scored 1, 2, 3, 4, and 5, respectively, and then $5,4,3,2$, and 1 points. The three-dimensional scale has a simple structure and 
simple operation, and is widely used in many experimental studies. However, most of these scales have biased responses. When choosing an answer, internal customers may be too high or too low (Alavi et al., 2016; Zhuofan et al., 2016). The distortion of response may be biased towards internal customer satisfaction measurement. Another way to collect information is to use the method of mailing questionnaires when conducting customer satisfaction surveys to obtain raw data. This method is to send the designed questionnaire to the respondent. The respondent fills in the questionnaire according to the requirements of the questionnaire and sends it back to the respondent.

In the survey of tourism e-commerce user satisfaction, we used the scale survey method-Likert scale method, and used the telephone survey method to conduct a questionnaire survey. After obtaining the data, in the process of processing the data, we mainly use the relevant knowledge of discrete type 2 fuzzy sets and analytic hierarchy process to process the data and obtain the customer's satisfaction with travel e-commerce. Experimental results show that the overall satisfaction of travel e-commerce customers is of a general level. Tourism supporting services and contract fulfillment services have become the main factors affecting customer satisfaction. To improve and increase customer satisfaction, the tourism e-commerce platform should strengthen the management of tourism supporting services and contract fulfillment services. The experimental results illustrate that overall customer satisfaction is 2.6128. According to the division of the measurement scale of satisfaction level, it can be seen that the overall satisfaction of travel e-commerce customers belongs to the general level. The first-level fuzzy comprehensive evaluation is (0.0967 0.16960 .33660 .24690 .502$)$. According to the principle of maximum membership, the evaluation levels of R3 and R5 in the first-level fuzzy comprehensive evaluation are "unsatisfactory". It means tourism supporting services and contract fulfillment services become customer satisfaction. The main factor of degree. In order to improve and increase customer satisfaction, the tourism e-commerce platform should strengthen the management of tourism supporting services and contract fulfillment services.

\section{PROPOSED METHOD}

\subsection{Tourism E-Commerce Summary}

In the 21 st century, the global economy has entered an information age centered on the Internet. Whoever can grasp the information as quickly as possible can succeed. As the best platform, e-commerce provides a broad space for consumers and manufacturers to allow consumers and manufacturers to stay in business and communicate smoothly (Fabisiak, 2018). E-commerce has greatly changed the traditional business model with its advantages of low cost, high efficiency and wide range. It has become a new leader in the development of all countries in the world. Driven by the trend of this era, the industry, which is recognized as the most blessed industry and the most powerful and largest in the global economy. As a new development direction, e-commerce develops rapidly. It is an interactive business activity launched on the Internet in the context of the integration of the Internet and traditional information technology systems (Khatwani et al., 2018). Tourism e-commerce is the application of e-commerce in the special industry of tourism. Usually, people's concept of tourism e-commerce is understood from two aspects: the first is the online sales of tourism products and services, which is a narrowly understood concept of tourism e-commerce, the travel website through instant online services. Each tourist provides customized services; the second is e-commerce based on the entire tourism market, which is tourism e-commerce that is understood in a broad sense.

The travel e-commerce system can be divided into two categories according to whether it involves online payment: face-to-face payment or payment by electronic bank account or credit card. Considering the long-term development, the e-commerce system that the bank joins is the ultimate development destination and a complete e-commerce system (Pauluzzo et al., 2018). Tourism e-commerce can be divided into B2B components (websites for transportation, accommodation, attractions), B2C components (for tourists), C2B (visitors "a la carte", corporate bidding), C2C (sponsor-initiated). Recruitment of the same person to organize their own group and other modes. 


\subsection{Description and Analysis of Satisfaction Index Based on Discrete Two-Type Fuzzy Sets}

According to the Like-rt scale, the satisfaction is divided into five levels of "very satisfied", "relatively satisfied", "basically satisfied", "not very satisfied" and "very dissatisfied", using $V_{1}, V_{2}, V_{3}, V_{4}$ and $V_{5}$ indicate that the questionnaire area $\mathrm{U}=\left\{u_{1}, u_{2} \ldots, u_{n}\right\}$ is a discrete domain, and $\mathrm{j}$ two-type fuzzy sets $A_{i j}$ are defined on $u_{i}(\mathrm{i}=1,2, \ldots, \mathrm{n})$, where $A_{i j}$ indicates that indicator $r_{i}$ is Fuzzy set of grade $V_{j}$.

Fuzzy comprehensive evaluation of passenger satisfaction:

1. Determine the set of systematic evaluation factors. According to the customer evaluation index system established by layering, the first level factor set $\mathrm{U}=\left\{U_{1}, U_{2}, \ldots U_{n}\right\}$ can be established, and each factor in the first level factor set is determined by several factors of the second level, thereby establishing the second level of a factor set $U_{1}=\left\{U_{i 1}, U_{i 2} \ldots U_{i m}\right\}, \mathrm{i}=1,2 \ldots$ n. Determining the system evaluation factor set by analogy.

2. Determine the weight set of systematic evaluation. After the hierarchy and attribution of the factor set determined in the first step, the weight set $A=\left\{A_{1}, A_{2}, \ldots A_{n}\right\}$ of the first level factor set $U_{1}$ is established, and the weight set of the subset of the second level factors is $A_{i}=\left\{A_{i 1}\right.$, $\left.A_{i 2} \ldots A_{i m}\right\}, i=1,2 \ldots n$. The analogy is used to determine the weight set of systematic evaluation.

3. Establish a first-level fuzzy comprehensive evaluation of evaluation set $\mathrm{V}$ and measurement scale vector $H$. The first-level fuzzy comprehensive evaluation is to evaluate each factor in the first layer of factors. The factor of the factor concentration is the $R_{j k}$ of the evaluation set $U_{i j}$, and the single factor fuzzy evaluation matrix is established. According to the weight vector of each factor in $U_{\mathrm{i}}$ and the single factor evaluation matrix of $U_{\mathrm{i}}$, the first-level fuzzy comprehensive evaluation model is established: $B_{i}, A_{i}, R_{i}$.

4. Two-level fuzzy comprehensive evaluation. Taking each factor as an element, as a result of its single factor evaluation, a comprehensive fuzzy evaluation matrix can be obtained. According to the weight vector of $\mathrm{U}$ and the evaluation matrix, the second-level fuzzy comprehensive evaluation model is established as: $B=A * R$.

5. Calculate customer satisfaction $\mathrm{S}=\mathrm{B} * \mathrm{HT}$.

\subsection{Customer Satisfaction Calculation and Analysis}

1. Establish a set of systematic evaluation factors. According to the travel e-commerce customer evaluation index system shown in this paper, a two-level factor set can be established. The first level factor set is $\mathrm{U}=\left\{U_{1}, U_{2}, U_{3}, U_{4}, U_{5}\right\}$, including $U_{1}$ management service $U_{2}$, tour guide service, $U_{3}$ travel support service, $U_{4}$ attraction tour service, $U_{5}$ contract fulfillment service. The second level factor set is derived from the decomposition of these five factors.

2. Establish a set of weights at each level. Using the variance contribution rate (eigenvalue) of the factor as the weight of the factor, the SPSS statistical software is used to perform factor analysis on the measured data of the index, thereby obtaining a weight set.

The first step is to obtain the variance contribution (eigenvalue) of the first-level factor concentration factor, which is an indicator to measure the importance of the factor. As shown in Table 1 . The variance contribution (eigenvalue) reflects the ability of the factor to interpret the total variance of all factor variables. The higher the value, the higher the factor important. Therefore, the variance contribution (eigenvalue) of the factor is taken here as the weight of the first level factor. 
Table 1. Variance contribution (eigenvalue)

\begin{tabular}{|l|l|}
\hline Management service $U_{1}$ & 2.487 \\
\hline Tour guide service $U_{2}$ & 2.251 \\
\hline Travel support service $U_{3}$ & 2.224 \\
\hline Attractions tour service $U_{4}$ & 1.856 \\
\hline Contract travel service $U_{5}$ & 1.826 \\
\hline
\end{tabular}

The second step is to obtain the factor load matrix of the second level factor set. The factor load matrix reflects the relationship between the factors in the first layer of factors and the factors in the second layer. The larger the value, the closer the relationship between the two is, and the greater the weight assigned. Here, the load value is taken as the weight of the second level factor.

The third step is to normalize the obtained weight values, the results are shown in Table 2.

3. Establish an evaluation set and measure the scale phasor. Here, the 5-level standard is used to establish an evaluation set $\mathrm{V}=$ \{ satisfactory, more satisfactory, generally, less satisfied, not satisfied\}, using the 5-level Likert scale for assignment, and obtaining the corresponding

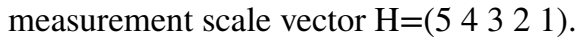

4. First-level fuzzy comprehensive evaluation. According to the tourism survey questionnaire, the evaluation results are obtained, and the evaluation scale is used to score, and the comprehensive fuzzy evaluation matrix $\mathrm{R}$ of the evaluation results is obtained:

$$
\begin{aligned}
& \begin{array}{lllll}
0.1 & 0.13 & 0.33 & 0.27 & 0.17
\end{array} \\
& R_{1}=0.1 \quad 0.21 \quad 0.29 \quad 0.24 \quad 0.16 \\
& \begin{array}{lllll}
0.09 & 0.17 & 0.39 & 0.23 & 0.12
\end{array} \\
& B_{1}=A_{1} \times R_{1}=\left(\begin{array}{lll}
0.34 & 0.33 & 0.33
\end{array}\right) * \\
& \begin{array}{lllll}
0.1 & 0.13 & 0.33 & 0.27 & 0.17
\end{array} \\
& R_{1}=0.1 \quad 0.21 \quad 0.29 \quad 0.24 \quad 0.16 \\
& \begin{array}{lllll}
0.09 & 0.17 & 0.39 & 0.23 & 0.12
\end{array}
\end{aligned}
$$

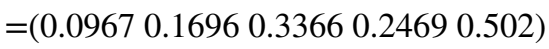

Indicates that the management service is in the evaluation of the various levels of comments in the evaluation set $V$.

The same reason:

$\mathrm{B} 2=(0.24440 .26330 .31980 .11180 .0608)$ 
Table 2. Weight set

\begin{tabular}{|c|c|c|}
\hline $\begin{array}{l}\text { First factor set } \\
U_{i} \text { Weights } A_{i}\end{array}$ & Second factor set $U_{i j}$ & Weights $A_{i j}$ \\
\hline & Service attitude $U_{11}$ & 0.34 \\
\hline & service method $U_{12}$ & 0.33 \\
\hline \multirow[t]{4}{*}{ Management service $U_{1} 0.23$} & Service efficiency $U_{13}$ & 0.33 \\
\hline & Organizational skills $U_{14}$ & 0.29 \\
\hline & Communication skills $U_{21}$ & 0.27 \\
\hline & Explanatory ability $U_{22}$ & 0.23 \\
\hline \multirow[t]{4}{*}{ Tour guide service $U_{2} 0.21$} & Coordination $U_{23}$ & 0.21 \\
\hline & Transportation service $U_{24}$ & 0.28 \\
\hline & Catering Services $U_{31}$ & 0.27 \\
\hline & Accommodation service $U_{32}$ & 0.25 \\
\hline \multirow[t]{3}{*}{ Tour guide service $U_{3} 0.21$} & Shopping service $U_{33}$ & 0.2 \\
\hline & Line arrangement $U_{34}$ & 0.3 \\
\hline & Landscape features $U_{41}$ & 0.25 \\
\hline \multirow[t]{2}{*}{ Tour guide service $U_{4} 0.18$} & Tour environment $U_{42}$ & 0.23 \\
\hline & Ornamental value $U_{43}$ & 0.22 \\
\hline
\end{tabular}

Indicates that the tour guide service factor is in the evaluation of the various levels of comments in the evaluation set $V$ :

$\mathrm{B} 3=(0.03830 .05040 .18960 .32560 .3961)$

It indicates that the tourism supporting service factor is in the membership of the evaluation set V:

$\mathrm{B} 4=(0.06770 .04480 .36120 .23850 .2878)$ 
It indicates that the tourist attraction service factor is in the membership of the evaluation set $\mathrm{V}$ :

$\mathrm{B} 5=(0.0680 .06810 .22670 .2990 .3382)$

Indicates that the contract fulfillment service factor is in the evaluation of the membership of each level in the evaluation set $V$.

5. Two-level fuzzy comprehensive evaluation:

$$
\begin{aligned}
& B=A \times R=(0.23,0.21,0.21,0.18,0.17) * \\
&= \begin{array}{lllll}
* 0967 & 0.1696 & 0.3366 & 0.2469 & 0.502 \\
0.2444 & 0.2633 & 0.3198 & 0.1118 & 0.0608 \\
0.0383 & 0.0504 & 0.1896 & 0.3256 & 0.3961 \\
& & & & \\
0.0677 & 0.0448 & 0.3612 & 0.2385 & 0.2878 \\
0.068 & 0.0681 & 0.2267 & 0.299 & 0.3382
\end{array}=(0.1053,0.1245,0.2879,0.2424,0.2398)
\end{aligned}
$$

Representation of the overall satisfaction of tourism e-commerce customers in the evaluation set V.

6. Overall customer satisfaction:

$$
S=B \times T=(0.1053,0.1245,0.2879,0.2424,0.2398) \times\left[\begin{array}{l}
5 \\
4 \\
3 \\
2 \\
1
\end{array}\right]=2.6128
$$

According to the above-mentioned satisfaction level measurement scale vector division, it can be seen that the overall satisfaction of tourism e-commerce customers is a general level. According to the principle of maximum membership degree, the evaluation grades of R3 and R5 in the firstlevel fuzzy comprehensive evaluation are "unsatisfactory". Tourism supporting services and contract fulfillment services become the main factors affecting customer satisfaction. In order to improve customer satisfaction, the tourism e-commerce platform should strengthen the management of tourism supporting services and contract fulfillment services.

\subsubsection{Sampling Method and Sample Size Calculation Method}

Using cluster random sampling method, a total of 30 tourism institutions were selected, and then the sample of each tourism institution's tourist satisfaction was randomly sampled.

The confidence level $\alpha$ is taken as $95 \%$ two-sided test, and the allowable error is 0.03 , calculated according to the following sample size estimation formula:

$$
N=\frac{Z_{\alpha}^{2} \times p_{0} \times\left(1-p_{0}\right)}{\sigma^{2}}
$$




\subsection{Classical Measurement Theory}

1. Validity analysis: The validity analysis of this study selects structure validity analysis. Since the survey questionnaire of the organization's tourism service satisfaction has no solid theoretical foundation as support in previous studies, the exploratory factor analysis is first carried out on the observed variables of the survey results to obtain a theory on the internal structure of the tourism service satisfaction questionnaire. To this end, this study randomly divides the data surveyed by each tourism service agency into two halves, half for exploratory factor analysis and the remaining half for confirmatory factor analysis.

2. Exploratory factor analysis: Exploratory factor analysis is mainly to find the comprehensive index that affects the observed variable, that is, factor, through principal component analysis. This study uses exploratory factor analysis to observe the internal structure of tourism service satisfaction items and uses it as the basis for the next step of confirmatory factor analysis. The realization of exploratory factor analysis mainly consists of the following four steps:

a. First, perform KMO test and Bartlett spherical test on the observation data to determine whether the obtained observation data meet the requirements of exploratory factor analysis;

b. After the first step meets the requirements, perform principal component analysis on the observation data, extract the number of principal components with a cumulative contribution rate greater than $70 \%$ and feature roots greater than one as the number of public factors, and form the dimension of the tourism service satisfaction questionnaire;

c. Select the maximum variance rotation method to calculate the factor load matrix;

d. Divide different factors into different dimensions through factor scores.

3. Confirmatory factor analysis: Confirmatory factor analysis mainly models prior information to fit the actual data. Here, the factor structure of the previous exploratory factor analysis is tested. The confirmatory factor analysis model is classified as a structural equation model. SEM integrates two statistical methods, factor analysis and path analysis, to identify, estimate, and verify various causal models. This study uses the first-order confirmatory factor analysis model in the structural equation to verify the hypothetical model, and observes whether the model fits the actual data through the degree of fit.

The main contents of the analysis are: the public factor extracted by exploratory factor analysis is used as the latent variable of the structural equation model, and the observation data of the satisfaction questionnaire is used as the obvious variable. The maximum likelihood method was used to calculate the standardized regression coefficients, covariance, residual variance, and multivariate correlation square values, and the sample matrix, combined reliability, and average variance were calculated. Simultaneously commonly used fitness evaluation indexes were calculated.

Among them, the combined reliability as the reliability coefficient of the latent variable in the structural equation model is one of the criteria for determining the internal quality of the model. When the combined reliability value is greater than 0.6 , it indicates that the internal quality of the model is good, and its concept is different from that in reliability analysis. The average variance extraction can directly show how much of the variance explained by the latent variable comes from the measurement error. The larger the value, the larger the index variable explained by the latent variable and the smaller the relative measurement error. The calculation formulas are:

$\rho_{c}=\frac{(\Sigma \lambda)^{2}}{\left[(\Sigma \lambda)^{2}+\Sigma(\theta)\right]}$ 
$\rho_{v}=\frac{(\Sigma \lambda)^{2}}{\left[\Sigma \lambda^{2}+\Sigma(\theta)\right]}$

In the above formula symbols, $\rho_{c}$ is the combined reliability, $\rho_{v}$ is the average variance extraction, and $\lambda$ is the estimated value of the standardized parameter of the observed variable on the latent variable (normalized factor load). $\theta$ is the amount of error variation of the observed variable, its value $=1$-the square of the normalized factor load.

4. Calculation of internal consistency reliability coefficient: Cronbach's $\alpha$ coefficient is commonly used to evaluate the questionnaire's internal consistency. Especially for the reliability evaluation of Likert scale, the higher the Cronbach's $\alpha$ coefficient, the better the scale's internal consistency. The formula for calculating Cronbach's $\alpha$ coefficient is:

$\alpha=\frac{K}{K-1}\left[1-\frac{\Sigma S_{i}^{2}}{S^{2}}\right]$

In the above formula, $\mathrm{K}$ is the number of entries of the entire scale or subscale, $\mathrm{Si} 2$ is the variance of the i-th entry, and S2 is the variance of the score of the entire scale or subscale. It is generally believed that the Cronbach's $\alpha$ coefficient of the total scale is preferably above 0.80 , and the Cronbach's $\alpha$ coefficient between 0.70 and 0.80 is the acceptable range of the total scale. Correspondingly, the Cronbach's $\alpha$ coefficient of the subscale is preferably above 0.70 , and the Cronbach's $\alpha$ coefficient of 0.60-0.70 can also be considered to be internally consistent.

Sex is better.

\subsection{Linear Weighted Sum Method}

The linear weighted sum method is an evaluation function method, which is to give it a corresponding weight coefficient according to the importance of each goal, and then optimally solve its linear combination, which is often used in multi-objective programming problems. In this study, the weights of the observation indexes in each dimension using the structural factor load factor are determined, and then linear weighting is performed according to the weights of different observation variables in each dimension. Assuming that there are $\mathrm{m}$ plans to be evaluated and $\mathrm{n}$ observation indicators to form the original data matrix, then:

$$
X=\left(x_{i j}\right)_{m \times n},(1 \leq i \leq m, 1 \leq j \leq n)_{x_{i j}}
$$

According to the principle of the linear weighted sum method and the weights obtained by the structural equation, the calculation formula for the comprehensive evaluation value $\mathrm{Zi}$ of each scheme is:

$Z_{i}=\sum_{j=1}^{n} w_{j} x_{i j}$

In this study, the comprehensive evaluation value is calculated by the above formula based on the data obtained from the satisfaction statistics of the travel staff of the surveyed tourism service 
organizations, and the relative data sorting of the satisfaction of the travel staff of the surveyed travel service organizations is performed according to the evaluation values.

\section{EXPERIMENTS}

\subsection{Experimental Methods and Experimental Tools}

Through the use of the scale survey method - the Likert scale method, and through the survey, the executives of several travel companies are asked to understand the passengers' perception of tourism e-commerce in recent years, as well as the annual tourism. The number of times, travel feedback information to observe. Through the investigation of relevant factors that have an impact on tourism e-commerce, we will further understand the relevant situation of passengers' satisfaction with tourism e-commerce.

\subsection{Data Extraction and Processing Methods}

In order to better understand the customer's satisfaction with travel e-commerce, the authors designed a questionnaire to further understand the customer's satisfaction with travel e-commerce and the factors affecting customer satisfaction. The design form establishes three levels of indicators. The first level indicator is the overall customer satisfaction. The second level indicator sets five major aspects, namely management service, tour guide service, travel support service, scenic spot tour service, and contract fulfillment service. The third-level indicator is the refinement of the secondary indicators, which divides the management services into service attitudes, service methods, and service efficiency. Refine tour guide services into organizational, communication, explaining and coordination skills. The tourism supporting services are refined into transportation services, catering services, accommodation services, and shopping services. Refine the scenic tour service into line arrangement, landscape features, tour environment and ornamental value. The contract fulfillment services are refined into the consistency of tourism content, the consistency of service standards, the consistency of travel expenses, and the safety of travel. A mailing survey on residents of the three provinces of Jiangxi, Zhejiang, and Fujian was conducted. A total of 500 questionnaires were sent, and 397 were collected, of which 322 were valid. Repeat this many times. Through the data collation and statistics, using EXCEL and SPSS statistical software for statistical analysis to obtain specific indicators, as the basis of this study.

In this paper, the data is obtained by mailing the questionnaire survey, and a reward is set for answering the question. The reward is the largest in the specified time interval (the time of the normal answer). The remaining draws are awarded and the data is not used. The questionnaires that answer the questions in a reasonable time are sorted out and the drafts are used. Data processing uses a discrete type 2 fuzzy set. In social life, there is a lot of uncertain and inaccurate information. In response to this phenomenon, professor Zadeh extended the traditional classic set in 1965 and proposed the concept of fuzzy set. The fuzzy set includes two types: the type of fuzzy set and the type 2 fuzzy set. The membership value at each point is a certain number, which cannot be freely changed. Therefore, it exists certain limitations in solving problems such as data interference and language ambiguity. In order to solve this problem, the membership value at each point is fuzzified, so that the membership value at each point is a type-type fuzzy set defined on $[0,1]$, thus generating a type-type fuzzy set. It has its unique advantages when dealing with more uncertain information. In this present research work, the method of discrete two-type fuzzy sets is used.

\section{DISCUSSION}

\subsection{Economic Development Promotes Tourism}

With the improvement of China's economic level, we pay more attention to the quality and mode of spiritual life on the basis of pursuing material life, and tourism has gradually become an improvement 
in people's quality of life and methods. With the development of the economy, the scenic spots are constantly innovating in play projects and travel modes to better attract customers, enhance and fully exploit the economic potential of the scenic spot. With the economic development, the construction of tourist roads is gradually proceeding, which makes it more convenient for passengers to enter and leave, improving safety and convenience. Increase supervision over the catering hygiene of scenic spots to ensure the health of tourists. Improve the information construction of scenic spots, and strive to build a big data information network for tourism to facilitate the inquiry of customers' travel information (Li et al., 2018; Singh \& Agrawal, 2018). The development of the times is gradually improving the overall level of tourism.

The growth in domestic tourist traffic has slowed, but the number of tourists has been gradually increasing as shown in Figure 1.

After the downturn in 2016 and 2017, the number of outbound tourists in the first half of 2019 continued to grow at a high rate. According to the China Tourism Research Institute, the number of outbound tourists in the first half of 2019 was about 81.29 million, a year-on-year increase of $14 \%$.

\subsection{Policy Support Advantage Analysis}

China has entered the era of mass tourism. With the support of the government, the tourism system has been continuously improved in exploration, and the development of high-end tourism has been gradually developed to meet the needs of the public. The industry has continued to introduce new policies and gradually improve infrastructure and traffic conditions. Guided by Xi Jinping's new era of socialism with Chinese characteristics, it conforms to the new trend of upgrading of culture and tourism consumption, deepening the supply-side structural reform in the cultural and tourism fields, and exerting strength from both ends of supply and demand to continuously stimulate cultural and tourism consumption potential. Efforts have been made to improve China's cultural and tourism consumption facilities, to make the consumption structure more reasonable, to optimize the consumption environment, and to provide more cultural and tourism products and services. Introduce consumer benefits measures. Continue to promote the price reduction of state-owned scenic spots. All localities can, in light of actual conditions, formulate policies for the implementation of scenic spot ticket reduction, free opening of scenic spots in the off-season, discounted tickets for performances, cultural and tourism consumption seasons, consumer months, and digital entertainment consumption experiences. Under the premise of legal compliance, we encourage the issuance of joint bank cards for cultural and tourism consumption and give preferential interest to users such as discounts and

Figure 1. Number of domestic tourists in the first half of 2013-2019

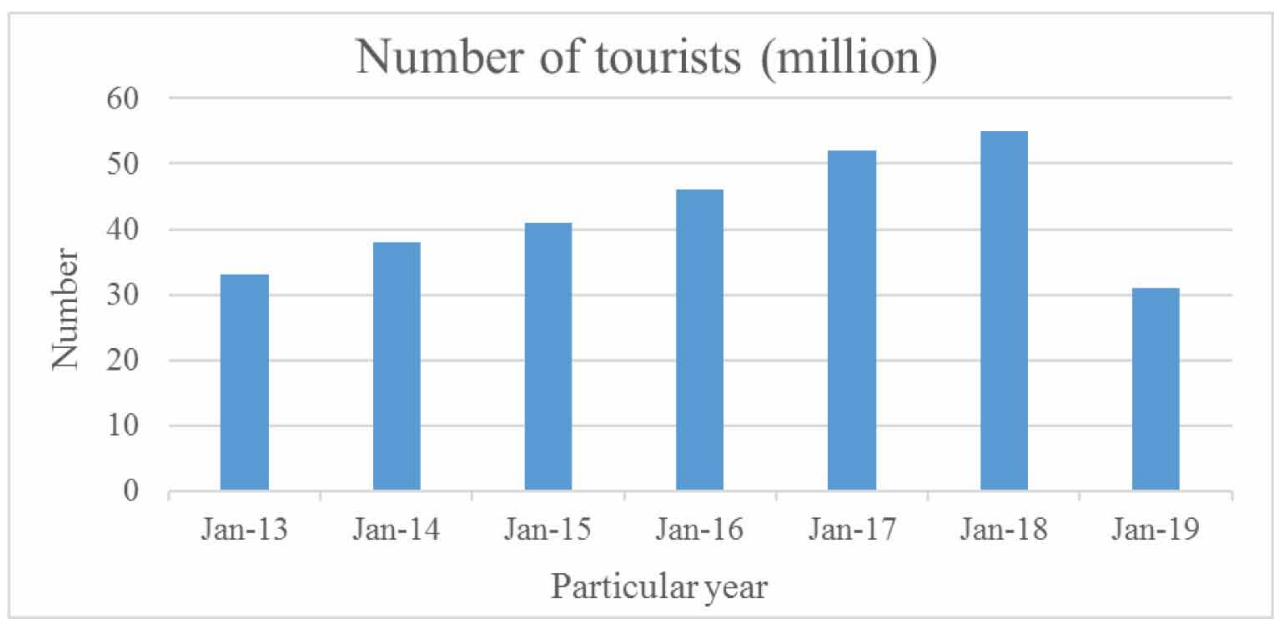


consumption instalments. Expanding the cultural and tourism consumer credit business, and innovating the consumer credit pledge model on the premise of standardizing development, and developing credit products with different down payment ratios, maturities and repayment methods.

Improve the convenience of consumption, promote the implementation of mobile payment convenience demonstration projects, improve the ease of use of bank cards in cultural and tourism consumption places, and promote the emerging payment methods of mobile Internet. Encourage the embedding of cultural consumption into various consumer places, relying on community life comprehensive service centers, urban and rural convenience consumer service centers. to create cultural consumption outlets around the masses. Encourage the renovation and upgrading of traditional performance venues and museums according to laws and regulations, and rationally support the dining area, audience rest area, Wenchuang product display sales area, bookstore, to create a better quality consumer environment. Guided performances, cultural entertainment, scenic spots and other places widely used Internet ticketing, two-dimensional code check. Improve the coverage level of broadband mobile communication networks in culture and tourism consumption places, and prioritize the deployment of fifth-generation mobile communication $(5 \mathrm{G})$ networks where conditions are met, and users have strong needs. Optimize tourism transportation services, scientifically plan routes, site settings, and provide intelligent travel information services. By 2022, in addition to cash payments, national cultural and tourism consumption sites can support bank cards or mobile payments. Internet ticketing and 4G/5G network coverage exceed $90 \%$, and cultural and tourism consumption is significantly improved.

In terms of services, the reservation function of the travel e-commerce website may arrange the tourist transportation, accommodation and other cumbersome matters without leaving the household, but the reservation function of the electronic travel website itself is not perfect. There is a certain gap between the user's evaluation value and the expected value of the function, and the satisfaction rate is $61.4 \% .53 \%$ of the users expect the service reservation function to be "higher" when using the travel e-commerce website, and only $8 \%$ of the users are satisfied with this function after using the travel network.

By comparison, it can be seen that the difference between the use of the user before use and the use of travel e-commerce is quite obvious, as shown in Figure 2.

Figure 2. Comparison of user evaluation before and after use
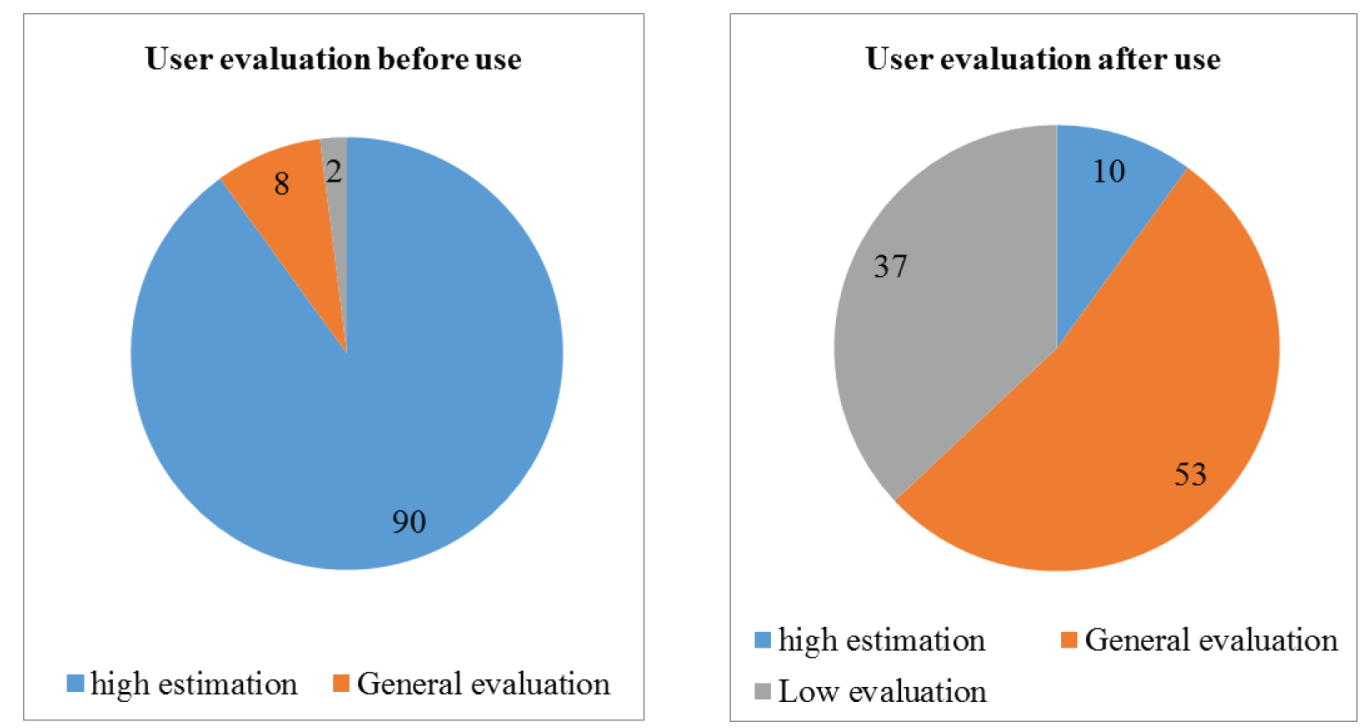
There is a significant increase in dissatisfaction before and after use, and the following analysis of user dissatisfaction reasons.

1. Percentage distribution of reasons why the user is dissatisfied with the predetermined function.

The proportion of reasons why the user is dissatisfied with the predetermined function is not satisfactory for the service reservation function. First of all, the copy service functions of each travel website are basically the same. There are no new service items, and there is no target service such as rescue service. According to the appointment of the meal. There was dissatisfaction with the advertising use of the trip (52\%). Secondly, $25 \%$ of users believe that the travel operators of travel e-commerce websites are not. Thus, they will not blindly book travel goods. Therefore, tourism e-commerce websites should work harder to establish a corporate reputation and clarify the travel list. The company's background, with or without permission, provides important information that users trust. However, $78 \%$ of low-education users believe that incomplete contact methods are also the main reason for travelers to make reservations when they book travel items on the website. Some websites only provide e-mail online booking, which will bring inconvenience to low-education users. The product was booked on the website, and the original plan was cancelled to contact the company provided on the travel website (Figure 3).

2. The reason why the user is dissatisfied with the information query function.

The query/consultation function of tourism information is becoming an important factor in guiding users to the website. According to the survey, the current e-commerce users' satisfaction with the website query function is $63.4 \%$, and $57 \%$ of travel e-commerce users use the travel website expectation. In the use of the "higher" information query service, only $7 \%$ of users are satisfied with the function after use. First of all, the link function of the travel website is not complete, the comprehensive search engine and the professional search engine cooperate not enough, $55 \%$ of users are dissatisfied with this function. Users cannot link properly, and even some links cannot be opened. Therefore, the charm of such a travel e-commerce website naturally declines. Second, on some travel e-commerce websites, the feedback rate of users' opinions and suggestions is too low (23\%) and the website $b$ does not have timely and free communication (22\%), which brings a lot of dissatisfaction to the travel e-commerce users (Figure 4).

\section{Figure 3. Unsatisfactory proportion of scheduled functions}

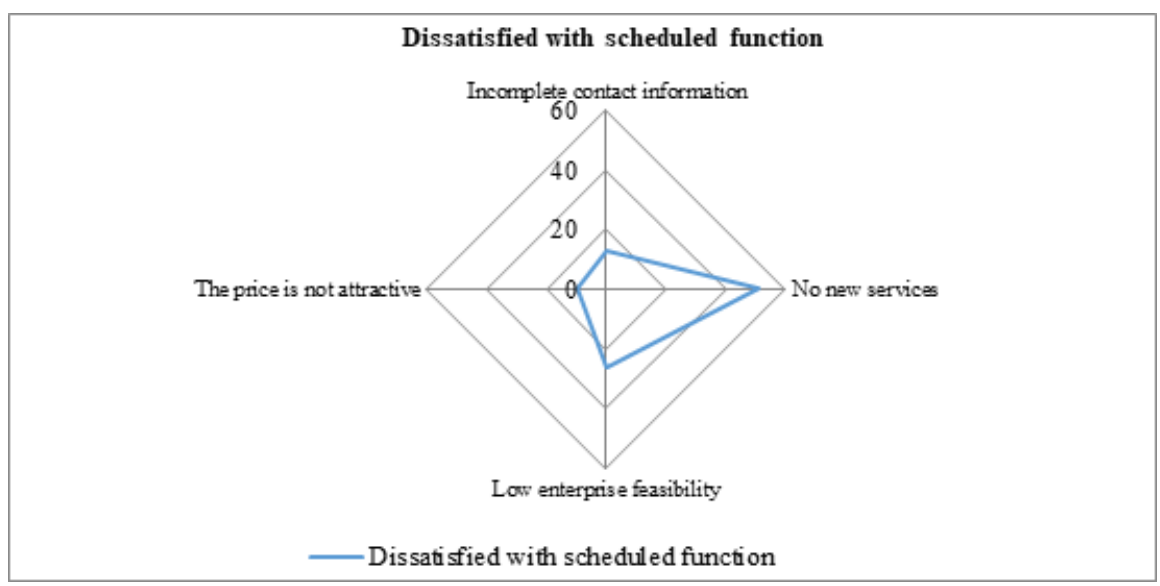


Figure 4. Information query function is not satisfied

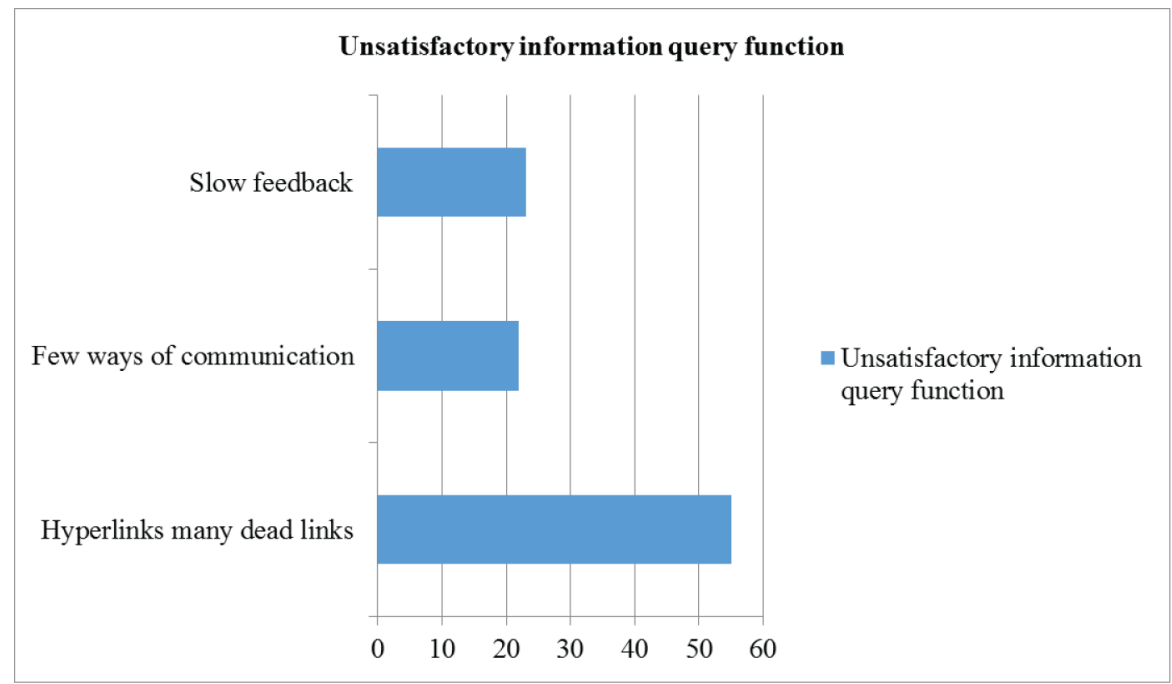

\section{CONCLUSION}

Since the reform and opening up, the number of Chinese tourists has gradually increased, but because of the low equipment and living conditions at that time, people's perception of tourism is not high. However, in recent years, the rapid development of China's tourism industry and the support of policies have gradually promoted the development of tourism. The rise of e-commerce in the past 20 years and the momentum has been very good. Tourism has gradually joined the platform of e-commerce, and e-commerce is also driving the development of tourism. Tourism follows the footsteps of e-commerce and is an important goal for the development of tourism.

After the downturn in 2016 and 2017, the number of outbound tourists continued to maintain rapid growth in the first half of 2019. According to statistics from the China Tourism Research Institute, the number of outbound tourists in the first half of 2019 was about 81.29 million, an increase of $14 \%$ year-on-year. The satisfaction of travel e-commerce users is $61.4 \%$, and $53 \%$ of users have a "higher" expectation value for the service reservation function when using the travel e-commerce website. However, after using the travel website, function is more satisfactory for only $8 \%$ of users. Dissatisfaction with travel advertising users (52\%) based on meal reservations and the like. Secondly, $25 \%$ of users think that the travel operator of a travel e-commerce website is not credible, so they will not blindly book travel goods. The satisfaction of current e-commerce users with the website query function is $63.4 \%, 57 \%$ of users of travel e-commerce use the travel website expecting to obtain a "higher" information query service when using it, and only seven users satisfy the function after use $\%$. First of all, the link function of the travel website is not complete, the comprehensive search engine and the travel professional search engine are not enough to cooperate, and 55\% of users are dissatisfied with this function. Secondly, on some travel e-commerce sites, the feedback rate of users' opinions and suggestions is too low (23\%), and there is no timely and free communication with website b (22\%), which has caused a lot of dissatisfaction with travel e-commerce users.

Through the above customer satisfaction analysis, this article draws the following conclusions:

1. Customer satisfaction with travel e-commerce is at a general level, and there is still much room for growth in the development of travel e-commerce. 
2. Customers are quite satisfied with the management services of tourist e-commerce, tour guide services and scenic tour services, but they have not done their best. On the existing basis, they must continue to work hard to develop.

\section{ACKNOWLEDGMENT}

This work was supported by the research foundation project of Yangtze Normal University (Grants No. 010730095). 


\section{REFERENCES}

Alavi, S., \& Ahuja, V. (2016). An empirical segmentation of users of mobile banking apps. Journal of Internet Commerce, 15(4), 390-407. doi:10.1080/15332861.2016.1252653

Choi, S. B., \& Kim, J. M. (2019). Multimedia mobile application e-commerce service satisfaction. Multimedia Tools and Applications, 78(5), 5217-5231. doi:10.1007/s11042-017-4865-9

Fabisiak, L. (2018). Web Service Usability Analysis Based on User Preferences. Journal of Organizational and End User Computing, 30(4), 1-13.

Getele, G. K., \& Jean, A. T. (2018). Impact of Business Process Re-Engineering (BPR) Implementation on Customer Satisfaction in E-Commerce Companies. Journal of Electronic Commerce in Organizations, 16(4), 41-52. doi:10.4018/JECO.2018100103

Hamidi, H., \& Moradi, S. (2017). Analysis of consideration of security parameters by vendors on trust and customer satisfaction in e-commerce. Journal of Global Information Management, 25(4), 32-45. doi:10.4018/ JGIM.2017100103

He, J., Liu, H., \& Xiong, H. (2016). SocoTraveler: Travel-package recommendations leveraging social influence of different relationship types. Information \& Management, 53(8), 934-950. doi:10.1016/j.im.2016.04.003

Hopp, T., \& Barker, V. (2016). Investigating the influence of age, social capital affinity, and flow on positive outcomes reported by e-commerce site users. Behaviour \& Information Technology, 35(5), 380-393. doi:10.1 080/0144929X.2016.1166520

Khatwani, G., \& Srivastava, P. R. (2018). Impact of Information Technology on Information Search Channel Selection for Consumers. Journal of Organizational and End User Computing, 30(3), 63-80. doi:10.4018/ JOEUC.2018070104

Neidhardt, J., Rümmele, N., \& Werthner, H. (2017). Predicting happiness: User interactions and sentiment analysis in an online travel forum. Information Technology \& Tourism, 17(1), 101-119. doi:10.1007/s40558-017-0079-2

Pauluzzo, R., \& Geretto, E. F. (2018). Validating the EUCS Model to Measure the Level of Satisfaction of Internet Users in Local Banks in Italy. Journal of Organizational and End User Computing, 30(1), 66-81. doi:10.4018/JOEUC.2018010104

Pereira, H. G., de Fátima Salgueiro, M., \& Rita, P. (2016). Online purchase determinants of loyalty: The mediating effect of satisfaction in tourism. Journal of Retailing and Consumer Services, 30, 279-291. doi:10.1016/j. jretconser.2016.01.003

Pilelienè, L., \& Grigaliūnaitè, V. (2016). A model of website quality-based e-commerce satisfaction index. Scientific Annals of Economics and Business, 63(1), 29-46. doi:10.1515/saeb-2016-0103

Ravi, L., Subramaniyaswamy, V., Vijayakumar, V., Chen, S., Karmel, A., \& Devarajan, M. (2019). Hybrid location-based recommender system for mobility and travel planning. Mobile Networks and Applications, 24(4), 1226-1239. doi:10.1007/s11036-019-01260-4

Shen, H. (2017). Modern information technology application in online travel service and hotel cooperation. Boletin Tecnico/Technical Bulletin, 55(4), 252-259.

Suel, E., \& Polak, J. W. (2017). Development of joint models for channel, store, and travel mode choice: Grocery shopping in London. Transportation Research Part A, Policy and Practice, 99, 147-162. doi:10.1016/j. tra.2017.03.009

Ting, B., \& Nam, I. (2016). A Comparative Study on Antecedents to the Customer Satisfaction with CrossBorder E-commerce in Korea and China. Asia Marketing Journal, 18(2), 63-93. doi:10.15830/amj.2016.18.2.63

Tsai, S. B. (2018). Using the DEMATEL Model to Explore the Job Satisfaction of Research and Development Professionals in China's Photovoltaic Cell Industry. Renewable \& Sustainable Energy Reviews, 81, 62-68. doi:10.1016/j.rser.2017.07.014

Wail, D. (2018). Analysis of customer satisfaction level on e-commerce web fashion product. Journal of Theoretical and Applied Information Technology, 96(14). 
Xiao, G., Cheng, Q., \& Zhang, C. (2019). Detecting Travel Modes Using Rule-Based Classification System and Gaussian Process Classifier. IEEE Access: Practical Innovations, Open Solutions, 7, 116741-116752. doi:10.1109/ACCESS.2019.2936443

Yang, L., \& Ma, Y. (n.d.). Application of an Improved Neural Network Algorithm in E-commerce Customer Satisfaction Evaluation. Academic Press.

Yin, D. (2018). Research on Fuzzy Comprehensive Evaluation of Passenger Satisfaction in Urban Public Transport. Modern Economy, 9(3), 528-535. doi:10.4236/me.2018.93034

Zhang, R., Zhang, X., \& Liu, L. (n.d.). Construction and Empirical Study on the Evaluation Model of E-commerce Logistic Satisfaction. Academic Press.

Zhuofan, Y., \& Yong, S. (2017). Analysis on e-commerce firm-level total factor productivity change and its impact factors. Systems Engineering-Theory \& Practice, 37(2), 431-439.

Guanghai Tang was born in Liangping, Chongqing, P.R. China, in 1975. He received the Doctoral degree from Xian Jiaotong University, P.R. China. Now, He works in School of Management, Yangtze Normal University, and his research interests include industrial economics and E-Commerce.

Hui Zeng was born in Luanxian, Hebei, P.R. China, in 1975. She received the Doctoral degree from PLA Institute of Military Economics, P.R. China. Now, she works in School of Management, Yangtze Normal University, and her research interests include industrial economics and Information economics. 